\title{
BP-Cx1-Platinum Complex BP-C1
}

National Cancer Institute

\section{Source}

National Cancer Institute. BP-CX1-Platinum Complex BP-C1. NCI Thesaurus. Code C107387.

A combination agent composed of the benzo-poly-carbonic-acid polymer BP-Cx1 chelated to platinum with potential antineoplastic activity. Upon intramuscular injection, the polymer moiety of BP-Cx1-Platinum Complex BP-C1 (BP-C1) alters the permeability of the cell membranes, which allows for increased penetration of platinum into tumor cells. In turn, platinum binds to nucleophilic groups such as GC-rich sites in DNA and induces intrastrand and interstrand DNA cross-links, as well as DNA-protein cross-links. These cross-links result in apoptosis and cell growth inhibition. In addition, the BP-Cx1 ligand is able to stimulate the innate immune system and upregulates a variety of cytokines including interferon, tumor necrosis factor-alpha (TNF-alpha), granulocyte macrophage-colony stimulating factor (GM-CSF), and various interleukins (ILs) such as IL6 and IL-25. In comparison to cisplatin and other platinum-based compounds, treatment with BP-C1 allows for less platinum administration, which reduces platinum-associated systemic toxicity and side effects, and enhances the safety profile while maintaining or improving its efficacy. 